\title{
Potential Risks Associated with Japanese Encephalitis Prevalence in Shandong Province, China
}

\author{
Qiqi Shi, ${ }^{1,2}$ Xiao Song, ${ }^{1}$ Yeyuan Lv, ${ }^{1}$ Xiaodan Huang, ${ }^{1}$ Jingxuan Kou, ${ }^{1}$ Huai Wei Wang, ${ }^{1}$ \\ Haobing Zhang, ${ }^{2}$ Peng Cheng, ${ }^{1}$ and Maoqing Gong ${ }^{1}$
}

\begin{abstract}
Japanese encephalitis (JE), which is caused by the Japanese encephalitis virus (JEV), is a zoonotic, vectorborne neurotropic disease that remains a major cause of viral encephalitis in Asia. JEV is spread to humans through mosquitoes, and its primary transmission vector is Culex tritaeniorhynchus. Mosquitoes were sampled from three collection sites: Hanzhuang town in Weishan County, Taibai Lake in Jining city, and Dongping Lake in Shandong Province, China. Pyrethroid insecticide resistance bioassays were conducted using adult mosquitoes. Cx. tritaeniorhynchus and $C$. pipiens pallens populations in Hanzhuang town and Dongping Lake showed resistance to pyrethroid insecticides, and populations in Taibai Lake showed incipient resistance. Coquillettidia ochracea populations in Hanzhuang town presented resistance as well, while in Taibai Lake, resistance was incipient. A total of 16,711 mosquitoes were collected, identified, and divided into 346 pools for JEV testing. Cx. tritaeniorhynchus had the advantage of being a local mosquito species. Overall, 31 (22.96) of the 135 pools of $C x$. Tritaeniorhynchus were positive for JEV. The overall maximum likelihood estimates of $C x$. tritaeniorhynchus, $C$. pipiens pallens, and Cq. ochracea indicated pooled infection rates of 5.29/1000 mosquitoes (95\% confidence interval $[\mathrm{CI}]=3.67-7.42), 1.60 / 1000$ mosquitoes $(95 \% \mathrm{CI}=0.82-2.85)$, and 6.39/ 1000 mosquitoes $(95 \% \mathrm{CI}=0.39-32.23)$, respectively. There were no significant differences in the pooled infection rates between the districts. The resistance to pyrethroids has increased the difficulty in controlling the mosquito vectors, especially JEV-positive mosquitoes. Given the changes in the JEV transmission vectors, the spatial and temporal diversity and the dynamic variety of mosquito species, insecticide resistance and global warming have the potential to facilitate the transmission of JE to humans.
\end{abstract}

Keywords: Japanese encephalitis, mosquitoes, vectors, resistance

\section{Introduction}

$\mathbf{J}$ APANESE ENCEPHALITIS (JE) is an infectious disease of the central nervous system caused by the Japanese encephalitis virus (JEV), a zoonotic mosquito-borne flavivirus. $\mathrm{JE}$ is prevalent in much of Asia and the western Pacific, with over 4 billion people at risk of infection (Yun and Lee 2014). $\mathrm{JEV}$ is spread to humans through mosquitoes; its primary transmission vector is Cx. tritaeniorhynchus (Li et al. 2011). Although an effective human vaccine has been available since 1954 (Impoinvil et al. 2013), JEV has persisted because it is sustained in an enzootic cycle, and nonvaccinated humans have a continual risk from infectious mosquito bites, especially nonvaccinated children. Throughout history, Shandong Province has been at the heart of the JE epidemic. According to statistics, Shandong had the highest morbidity rate in 1966, with 56.07/100,000 population (Xu et al. 1996). Unfortunately, in 2013, Shandong Province experienced a JE outbreak, with 407 confirmed cases, including 11 deaths (Zexin et al. 2018). The incidence of JE shows an obvious

\footnotetext{
${ }^{1}$ Shandong Institute of Parasitic Diseases, Shandong Academy of Medical Sciences, Jining, China.

${ }^{2}$ National Institute of Parasitic Diseases, Chinese Center for Disease Control and Prevention, Key Laboratory of Parasite and Vector Biology, MOH, National Center for International Research on Tropical Diseases, WHO Collaborating Centre for Tropical Diseases, Shanghai, China.

(C) Qiqi Shi et al. 2019; Published by Mary Ann Liebert, Inc. This Open Access article is distributed under the terms of the Creative Commons Attribution Noncommercial License (http://creativecommons.org/licenses/by-nc/4.0/) which permits any noncommercial use, distribution, and reproduction in any medium, provided the original author(s) and the source are cited.
} 
seasonal characteristic between July and September that peaks in August (Zhou and Zhou 2010). Notably, in August, the air temperature is enhanced with abundant rainfall, and the irrigation amount in paddy fields is increased. These favorable climatic conditions and survival environments drive mosquitoes to grow and breed quickly.

However, we have found that the major transmission vectors are not only $C x$. tritaeniorhynchus but also $C$. pipiens pallens and Coquillettidia ochracea. Furthermore, in some districts, $C$. pipiens pallens has become a dominant species, and its insecticide resistance has increased as well. Thus, there are some potential risks of JE occurrence in Shandong Province.

\section{Materials and Methods}

We collected mosquito samples from several national and provincial monitoring sites in Shandong Province, China (e.g., Hanzhuang town, Weishan county; Taibai Lake, Jining city; and Dongping Lake, Tai'an city) (Fig. 1) between June and September 2015. The mosquitoes were trapped using a mosquito net, transferred to a mosquito cage, and brought to the laboratory where they were frozen for $30 \mathrm{~min}$ in a $-20^{\circ} \mathrm{C}$ freezer. After freezing, the males and females were separated, and the males were discarded. The remaining females were transferred to new tubes at 50 mosquitoes per tube and stored in a $-80^{\circ} \mathrm{C}$ freezer. Before freezing, some samples were tested for resistance to a pyrethroid insecticide using the biological exposure cylinder recommended by the World Health Organization (WHO) (Liu and Chen 1979). The resistance level was measured by the tentative diagnostic dose and degree method of China. $M$ represents initial resis- tance with mosquito mortality between $80 \%$ and $97.9 \%$, and $\mathrm{R}$ represents resistance with mosquito mortality lower than $80 \%$.

A total of 16,177 mosquitoes were divided into 346 tubes, with $\sim 50$ mosquitoes per tube. The mosquito samples were homogenized and filtered, and the resultant filtrate was added to a culture tube with a monolayer of BHK-21 cells, cultured in an incubator with $5 \% \mathrm{CO}_{2}$ at $37^{\circ} \mathrm{C}$, and agitated gently every $15 \mathrm{~min}$ to facilitate viral infection. One hour later, the cell culture tube was removed from the incubator, and the medium was discarded. A total of $2 \mathrm{~mL}$ of cell maintenance solution was added, and the cells were cultured in an incubator with $5 \% \mathrm{CO}_{2}$ at $37^{\circ} \mathrm{C}$. The cells were monitored under a microscope every $24 \mathrm{~h}$ until lesions occurred on the cells, which were then harvested. The cells that showed suspicious lesions were subcultured continuously, and those that showed no lesions underwent three blind passages and were harvested.

We detected the nucleic acids of the JEV C/PrM gene segment by quantitative real-time PCR and nested PCR using 16,711 collected mosquitoes that were divided into 346 groups. First, we performed total RNA extraction from mosquitoes using the TRIzol method. For complementary DNA (cDNA) synthesis, a $10 \mu \mathrm{L}$ reaction volume consisted of $2 \mu \mathrm{L}$ of mixture RNA, $2 \mu \mathrm{L}$ buffer $(5 \times), 0.5 \mu \mathrm{L}$ reverse transcription (RT) mix (Takara), $0.5 \mu \mathrm{L}$ oligo dT, $0.5 \mu \mathrm{L}$ random primer, and $4.5 \mu \mathrm{L}$ diethyl pyrocarbonate (DEPC) treated water. For the RT reaction, the template was incubated at $37^{\circ} \mathrm{C}$ for $60 \mathrm{~min}$ and then terminated at $85^{\circ} \mathrm{C}$ for $5 \mathrm{~s}$. qPCR was performed with a Tiangen SuperReal PreMix Plus Kit and ABI PRISM Line Gene 9600 real-time fluorescent quantitative PCR system. The $20 \mu \mathrm{L}$ reaction volume

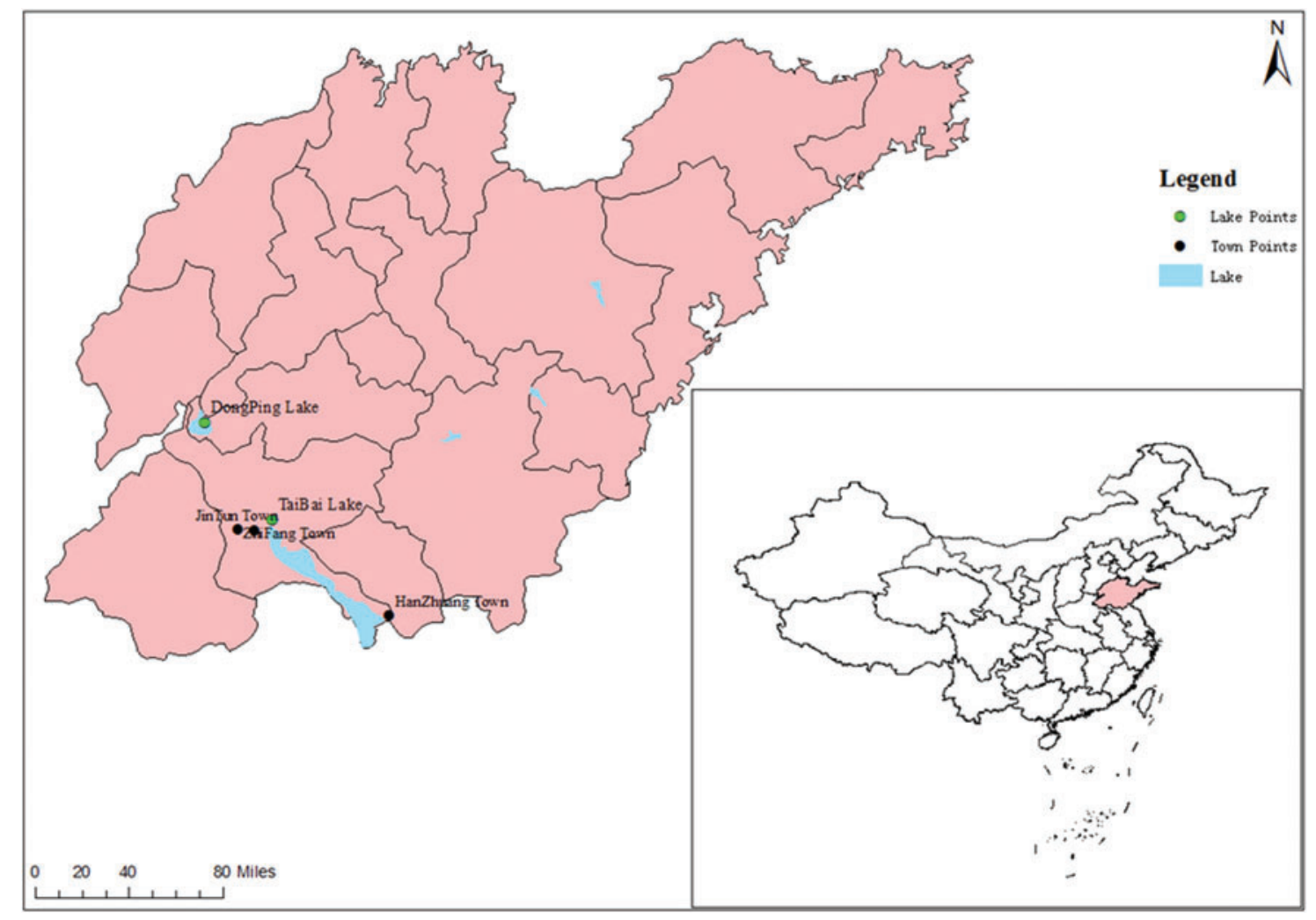

FIG. 1. Mosquito collection sites (Dongping Lake, Taibai Lake, Hanzhuang town) and dengue fever outbreak sites (Zhifang town and Jintun town). Color images are available online. 
consisted of $0.6 \mu \mathrm{L}$ forward (5'-AGA GCG GGG AAA AAG GTC AT-3') and $0.6 \mu \mathrm{L}$ reverse (5'-TTT CAC GCT CTT TCT ACA GT - $3^{\prime}$ ) primers; $10 \mu \mathrm{L} 2 \times$ SuperReal PreMix Plus, $2 \mu \mathrm{L} 5 \times$ ROX Reference Dye $\Delta, 2 \mu \mathrm{L}$ cDNA, and $4.8 \mu \mathrm{L}$ DEPC water. Thermocycling conditions were $95^{\circ} \mathrm{C}$ for $2 \mathrm{~min}$, 40 cycles of $95^{\circ} \mathrm{C}$ for $15 \mathrm{~s}, 55^{\circ} \mathrm{C}$ for $20 \mathrm{~s}$, and $72^{\circ} \mathrm{C}$ for $20 \mathrm{~s}$.

The first amplification of the C/PrM gene region of JEV by nested PCR was 647-bp, and the second amplification of the C/PrM gene region of JEV by nested PCR was 491-bp. The first nested PCR mixture was a $25 \mu \mathrm{L}$ total volume that included $12.5 \mu \mathrm{L}$ Taq Green Master Mix, 9.5 $\mu \mathrm{L}$ DEPC water,

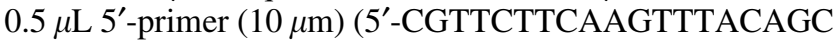
ATTAGC-3'), $0.5 \mu \mathrm{L} \quad 3^{\prime}$-primer $(10 \mu \mathrm{m}) \quad\left(5^{\prime}\right.$-CCYRTGT TYCTGCCAAGCATCCAMCC-3'), and $2 \mu \mathrm{L}$ cDNA. The second PCR mixture was a $25 \mu \mathrm{L}$ total volume that included 12.5 $\mu \mathrm{L}$ Taq Green Master Mix, 10.5 $\mu \mathrm{L}$ DEPC water, $0.5 \mu \mathrm{L}$ $5^{\prime}$-primer $(10 \mu \mathrm{M}) \quad\left(5^{\prime}\right.$-CGTTCTTCAAGTTTACAGCAT TAGC-3'), $0.5 \mu \mathrm{L} 3^{\prime}$-primer $(10 \mu \mathrm{M})\left(5^{\prime}\right.$-CGYTTGGAATG YCTRGTCCG- $3^{\prime}$ ), and $1 \mu \mathrm{L}$ of the first nested PCR product.

Thermocycle conditions for the first reaction were $94^{\circ} \mathrm{C}$ for $5 \mathrm{~min}, 35$ cycles of $94^{\circ} \mathrm{C}$ for $30 \mathrm{~s}, 55^{\circ} \mathrm{C}$ for $30 \mathrm{~s}, 72^{\circ} \mathrm{C}$ for $5 \mathrm{~s}$, and a final extension at $72^{\circ} \mathrm{C}$ for $10 \mathrm{~min}$. Thermocycle conditions for the second reaction were $94^{\circ} \mathrm{C}$ for $5 \mathrm{~min}, 40$ cycles of $94^{\circ} \mathrm{C}$ for $30 \mathrm{~s}, 57^{\circ} \mathrm{C}$ for $40 \mathrm{~s}, 72^{\circ} \mathrm{C}$ for $45 \mathrm{~s}$, and a final extension at $72^{\circ} \mathrm{C}$ for $10 \mathrm{~min}$. Then, nested PCR amplification products were detected by $1-2 \%$ agarose gel electrophoresis. When available, positive qPCR and nested PCR results were further investigated by sending the products for next-generation sequencing.

The maximum likelihood estimate for the mosquito infection rate was calculated using the software by Biggerstaff (2005) (www.cdc.gov/ncidod/dvbid/westnile/software.htm).

\section{Results}

We captured 16,711 individual mosquitos, including 17 species from six genera. The number of $C x$. tritaeniorhynchus, $C$. pipiens pallens, and Mansonia uniformis collected were $6610(39.55 \%), 6465$ (38.69\%), and 2357 $(14.10 \%)$, respectively. Mosquito density fluctuated with the seasons but peaked in August. Cx. tritaeniorhynchus and C. pipiens pallens populations in Hanzhuang town and Dongping Lake showed resistance to pyrethroid insecticides, and in Taibai Lake, populations showed incipient resistance. In addition, $\mathrm{Cq}$. ochracea populations in Hanzhuang town presented resistance as well, while in Taibai Lake resistance was incipient (Table 1). The real-time fluorescence qPCR assay showed that some mosquito samples were JEV positive, and the nucleic acids of JEV were detected in $C x$. tritaeniorhynchus, C. pipiens, and Cq. ochracea using a nested PCR assay, yielding minimum infection rates (MIRs) of 5.29/ 1000, 1.60/1000, and 6.39/1000 mosquitoes, respectively (Table 2 and Figs. 2 and 3). Subsequently, the sequencing of the C/PrM genes confirmed the identity of JEV.

\section{Discussion}

Hanzhuang town, Dongping Lake, and Taibai Lake are located in the densely populated Shandong section of the South-to-North Water Diversion Project. This area has humid and warm weather, as well as developed lake systems, that are suitable for mosquitoes to breed and propagate, generating a diversity of mosquito vector species. The areas

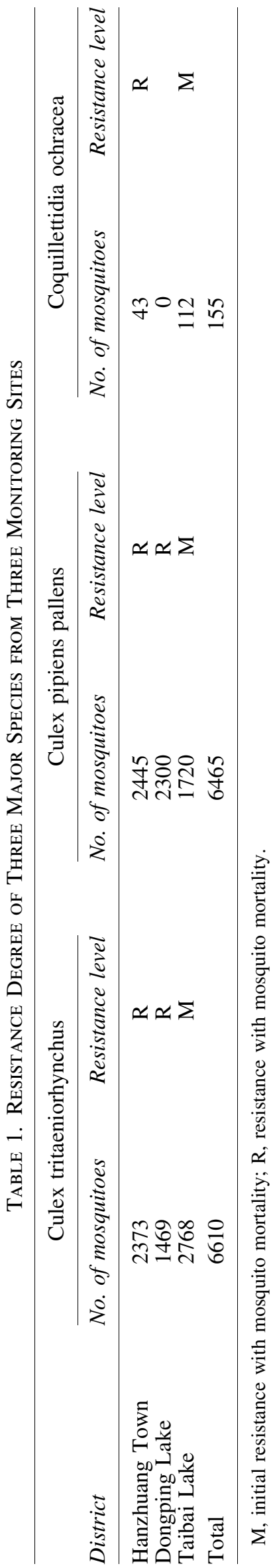


Table 2. Maximum Likelihood Estimate for Japanese Encephalitis Virus in Three Collection Sites

\begin{tabular}{|c|c|c|c|c|c|c|c|c|c|}
\hline \multirow[b]{2}{*}{ District } & \multicolumn{3}{|c|}{ Cx. tritaeniorhynchus } & \multicolumn{3}{|c|}{ C. pipiens pallens } & \multicolumn{3}{|c|}{ Cq. ochracea } \\
\hline & $\begin{array}{l}\text { No. of } \\
\text { pools }\end{array}$ & $\begin{array}{c}\text { No. of } \\
\text { positive } \\
\text { pools }\end{array}$ & $\begin{array}{c}\text { MLE per } 1000 \\
\text { mosquitoes } \\
(95 \% \text { CI) }\end{array}$ & $\begin{array}{l}\text { No. of } \\
\text { pools }\end{array}$ & $\begin{array}{c}\text { No. of } \\
\text { positive } \\
\text { pools }\end{array}$ & $\begin{array}{c}\text { MLE per } 1000 \\
\text { mosquitoes } \\
(95 \% \text { CI })\end{array}$ & $\begin{array}{l}\text { No. of } \\
\text { pools }\end{array}$ & $\begin{array}{c}\text { No. of } \\
\text { positive } \\
\text { pools }\end{array}$ & $\begin{array}{c}\text { MLE per } 1000 \\
\text { mosquitoes } \\
(95 \% \mathrm{CI})\end{array}$ \\
\hline $\begin{array}{c}\text { Hanzhuang } \\
\text { Town }\end{array}$ & 48 & 11 & $5.18(2.75-9.05)$ & 50 & 3 & $1.25(0.33-3.40)$ & 2 & 0 & $0(0.00)$ \\
\hline $\begin{array}{c}\text { Dongping } \\
\text { Lake }\end{array}$ & 30 & 5 & $3.65(1.37-8.13)$ & 47 & 4 & $1.80(0.59-4.33)$ & 0 & 0 & $0(0.00)$ \\
\hline Taibai Lake & 57 & 15 & $6.20(3.63-10.03)$ & 35 & 3 & $1.80(0.47-4.89)$ & 4 & 1 & $8.65(0.55-45.25)$ \\
\hline Total & 135 & 31 & $5.29(3.67-7.42)$ & 132 & 10 & $1.60(0.82-2.85)$ & 6 & 1 & $6.39(0.39-32.23)$ \\
\hline
\end{tabular}

CI, confidence interval; JEV, Japanese encephalitis virus; MLE, maximum likelihood estimate.

surrounding the lakes include tourist resorts with a high population mobility that is conducive to the spread of mosquito-borne diseases. After the South-to-North Water Diversion Project, the surface water level, catchment areas, vegetation, original breeding grounds, and quality of the water supply have changed, which in turn has changed the spatial and geographical distribution patterns of the mosquito communities and species diversity in Shandong Province. Based on our previous study, the seasonal fluctuations of adult mosquito species consistently appeared in June and reached a density peak in July to August (Tian et al. 2016). Therefore, we collected mosquitoes from June to September in this area to obtain the most representative data.

We examined the biological resistances of $C x$. tritaeniorhynchus, C. pipiens, and Cq. ochracea and found that the mosquito samples collected from Hanzhuang, Weishan, and Dongping Lake, Tai'an, were highly resistant to pyrethroid insecticides, whereas mosquitoes from Taibai Lake, Rencheng, were moderately resistant. The $C x$. tritaeniorhynchus-infested areas were mostly paddy fields, and the mosquito adults were commensal and rested in the shade of grasses and crops near their breeding ground during the daytime; therefore, they were often exposed to agricultural pesticides. At night, they flew into the houses of farmers and fed on humans and livestock; thus, they were extensively

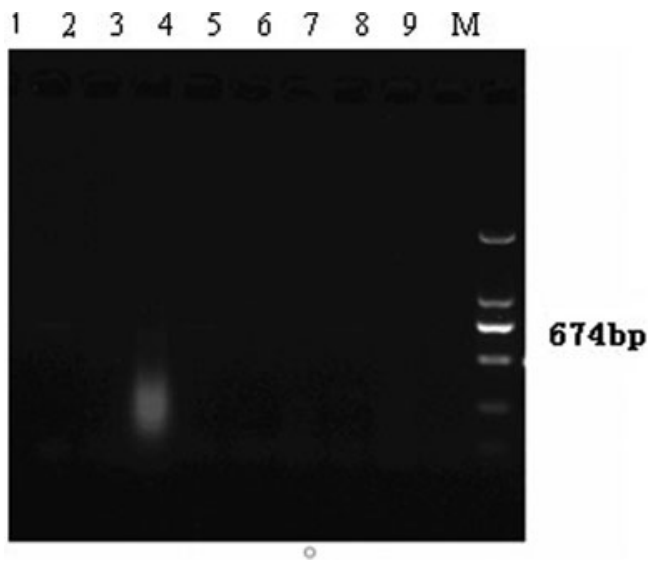

FIG. 2. The first amplification of the C/PrM gene region of JEV. JEV, Japanese encephalitis virus. Lanes $1-5, C x$. tritaeniorhynchus; lanes 6,8, C. pipiens pallen; lane 7, Cq. ochracea; lane M, 2000bp marker. exposed to various kinds of insecticides. Because of their extensive exposure to various kinds of pesticides, long artificial selection pressures on the mosquitoes have led them to develop high insecticide resistance. C. pipiens is a dominant commensal mosquito species in northern China. Recently, a series of activities have been initiated to create civilized and hygienic cities in Shandong Province, in which pyrethroids such as deltamethrin and beta-cypermethrin have been extensively applied to prevent and control mosquitoes, flies, rats, cockroaches, and other vermin, causing increased pyrethroid resistance among these pests. The low resistance shown in C. pipiens and Cx. tritaeniorhynchus collected from Taibai Lake is likely because this area is a tourist resort where pesticides are used less frequently.

The 346 batches of mosquito samples collected from the three monitoring sites were homogenized, and the supernatants were inoculated into BHK-21 cells. After three blind passages, no cell lesions were observed. Then, the cells were centrifuged, and the total RNA was extracted from the supernatant of the mosquito homogenate and then reverse transcribed to cDNA. After PCR amplification, the positively amplified products were submitted to Shanghai Biotech Co., Ltd. The results showed that they tested positive for the nucleic acids of JEV, indicating the presence of JEV in the supernatant of the mosquito homogenate. The absence of cell

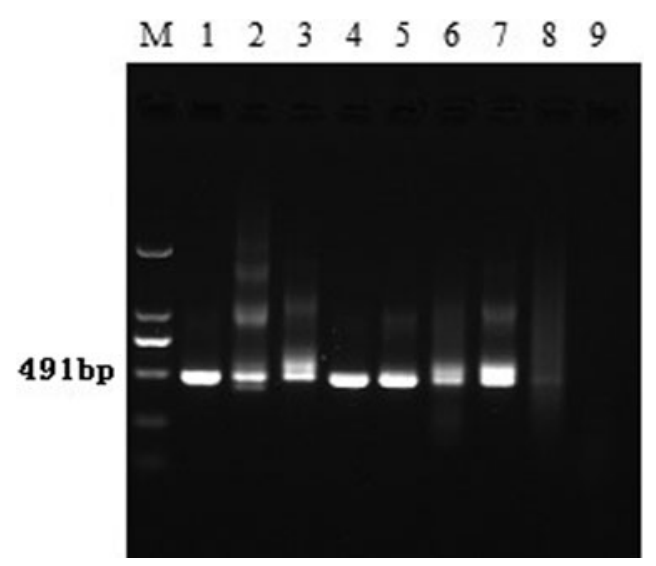

FIG. 3. The second amplification of the $\mathrm{C} / \mathrm{PrM}$ gene region of JEV. Lanes 1-5, Cx. tritaeniorhynchus; lanes 6,8, C. pipiens pallen; lane 7, Cq. ochracea; lane M, 2000bp marker. 
lesions was probably because the JEV concentration was too low or the JEV concentration in the blind passages was too diluted to cause cell lesions.

JEV-positive $C$. pipiens and $C x$. tritaeniorhynchus, especially highly insecticide-resistant mosquitoes, have undoubtedly increased the difficulty of controlling these mosquito vectors, further enhancing the risk of infection and the prevalence of JE. Adult mosquito control depends largely on insecticides. However, resistance to insecticides is rising globally (Mouchet 1972, Wesson 1990, Ponlawat et al. 2005, Cui et al. 2006, Chuaycharoensuk et al. 2011, Kamgang et al. 2011). The extensive use or nonregulated application of pesticides can hamper the efficacy of larvicide- and adulticide-based control programs, as demonstrated in the vector control of Aedes aegypti (Marcombe et al. 2009, Karunaratne et al. 2013) and Culex pipiens quinquefasciatus (Yebakima et al. 2004). From August 19 to October 11, 2017, Jintun and Zhifang townships in Jiaxiang County (Fig. 1), Shandong Province, had an outbreak of dengue fever. A total of 79 confirmed cases of dengue fever were reported, although without death. We monitored the densities of Aedes albopictus larvae and adults using the Breteau index (BI) method and the double-net method. Then, we investigated the density of A. albopictus in Qianli, Jintun Township, which was the core monitoring area. We found that the BI was 107, and the adult mosquito bite index was 17 mosquitoes per person per hour. Jiaxiang County, Shandong Province, has the highest latitude within the dengue fever epidemic zone in China. It has been reported that with global warming, the viability of mosquitoes in certain high-latitude regions has been enhanced, and their fecundity under favorable rainfall conditions has also increased, gradually expanding the prevalence range of JE (Yun and Lee 2014, Matthew et al. 2016). Given that the dengue virus and JEV originate from the same taxonomic flavivirus family (Flaviviridae), the two share similar viral structures, which are mostly single- and positive-stranded RNA viruses enveloped by symmetric icosahedral-like geometry. JEV can be vertically transmitted by $A$. albopictus through eggs, which is an important transmission pathway of the virus (Zhang et al. 1996, Han 2013). Thus, an outbreak of dengue fever partly increases the risk of JE prevalence, and it is necessary to address the insecticide resistance problem of $C$. pipiens and $C x$. tritaeniorhynchus.

Gao et al. (2015) performed a spatial dynamics analysis on JEV using the nucleotide sequence of the E gene of JE using the MigraPhyla program. The results showed that, as a major agricultural province, Shandong has a large rice planting area and a well-developed swine industry, which is conducive to the local circulation and the short-distance transmission of JEV (e.g., spread to Shanxi Province). Shandong Province is also home to important ports in China (Sun and Zhang 2012). A busy trade port is conducive to the spread of JEV; for example, JEV can be spread to South Korea and southern China through mosquitoes carried by ships. Thus, spatial spread and migration could, to some degree, lead to a resurgence of JE.

We should actively monitor JEV carried by local mosquitoes and the insecticide resistance of the mosquito populations, as well as improve public awareness of JE vaccination and strengthen JE control and prevention efforts. The potential for reemergence should receive substantially more attention from economic, agricultural, and environ- mental planning bodies. Changes in the JEV transmission vectors, the spatial and temporal diversity, and the dynamic variety of mosquito species caused by insecticide resistance and global warming have the potential to facilitate the transmission of JE to humans. Thus, understanding these potential factors in JE transmission is critical for shaping future surveillance and control strategies.

\section{Acknowledgments}

This work was supported by grants from the Natural Science Foundation of China $(81871685,81672059)$ and the Innovation Project of Shandong Academy of Medical Sciences, the key research and development plan of Shandong province (2018GSF118040).

\section{Author Disclosure Statement}

No competing financial interests exist.

\section{References}

Biggerstaff B. PooledInfRate Software. Vector Borne Zoonotic Dis 2005; 5:420-421.

Chuaycharoensuk T, Juntarajumnong W, Boonyuan W, Bangs MJ, et al. Frequency of pyrethroid resistance in Aedes aegypti and Aedes albopictus (Diptera: Culicidae) in Thailand. J Vector Ecol 2011; 1:204-212.

Cui F, Raymond M, Qiao CL. Insecticide resistance in vector mosquitoes in China. Pest Manag Sci 2006; 11:1013-1022.

Gao XY, Zhou HW, Liu H, Fu SH, et al. Spatial dissemination and migration events of Japanese encephalitis virus. Chin $\mathbf{J}$ Virol 2015; 3:264-268.

Han N. Genetic evolution and a comparative genomics analysis of dengue virus and Japanese encephalitis virus. University of Chinese Academy of Sciences, Beijing, 2013:1-162.

Impoinvil DE, Baylis M, Solomon T. Japanese encephalitis: On the One Health Agenda. In: Mackenzie JS, Jeggo M, Daszak $\mathrm{P}$, et al., eds. One Health: The Human-Animal-Environment Interfaces in Emerging Infectious Diseases. New York: Springer Berlin Heidelberg, 2013:205-247.

Kamgang B, Marcombe S, Chandre F, Nchoutpouen E, et al. Insecticide susceptibility of Aedes aegypti and Aedes albopictus in Central Africa. Parasit Vectors 2011; 4:79.

Karunaratne SH, Weeraratne TC, Perera MD, Surendran SN. Insecticide resistance and, efficacy of space spraying and larviciding in the control of dengue vectors Aedes aegypti and Aedes albopictus in Sri Lanka. Pestic Biochem Phys 2013; 1: 98-105.

Li YX, Li MH, Fu SH, Chen WX, et al. Japanese encephalitis in Tibet, China. Emerging Infect Dis 2011; 17:934-936.

Liu WD, Chen WM. Insecticide Resistance and Detection of Mosquitoes. Beijing: Science Press, 1979:1-14.

Marcombe S, Carron A, Darriet F, Etienne M, et al. Reduced efficacy of pyrethroid space sprays for dengue control in an area of Martinique with pyrethroid resistance. Am J Trop Med Hyg 2009; 5:745-751.

Matthew B, Christopher MB, Cyril C, Bhoj RJ, et al. Emergence or improved detection of Japanese encephalitis virus in the Himalayan highlands? Trans R Soc Trop Med Hyg 2016; 110:209-211.

Mouchet J. Survey of potential vectors of yellow fever in Tanzania. Bull World Health Organ 1972; 5:675-684. 
Ponlawat A, Scott JG, Harrington LC. Insecticide susceptibility of Aedes aegypti and Aedes albopictus across Thailand. J Med Entomol 2005; 5:821-825.

Sun YJ, Zhang HL. Genotypes of epidemic Japanese encephalitis virus in China and their distributions. Chin J Vector Biol Control 2012; 5:436-439.

Tian H, Guo XX, Yang PP, Huang XD, et al. Seasonal fluctuation of mosquitoes and insecticide resistance of Culex pipiens pallens in Taibai Lake area of Jining City. Chin J Hyg Insect Equip 2016; 3:250-252.

Wesson DM. Susceptibility to organophosphate insecticides in larval Aedes albopictus. J Am Mosq Control Assoc 1990; 2: 258-264.

Xu AQ, Liu GF, Song LZ, Hao SZ, et al. Investigation of the factors influencing the current prevalence of Japanese encephalitis in Shandong Province. Prev Med Lit Inf 1996; 2: 129-130.

Yebakima A, Marquine M, Rosine J, Yp-Tcha MM, et al. Evolution of resistance under insecticide selection pressure in Culex pipiens quinquefasciatus (Diptera, Culicidae) from Martinique. J Med Entomol 2004; 4:718-725.

Yun SI, Lee YM. Japanese encephalitis: The virus and vaccines. Hum Vaccin Immunother 2014; 2:263-279.

Zexin T, Guifang L, Min W, Huanyu W, et al. Molecular Epidemiology of Japanese Encephalitis Virus in Mosquitoes during an Outbreak in China, 2013. Korean J Parasitol 2018; 5:515-519.
Zhang HL, Mi ZQ, Zhang YZ. Investigation of the vertical transmission of Japanese encephalitis virus by Aedes albopictus. Chin J Virol 1996; 1:42-47.

Zhou CL, Zhou HN. Progress in the study of the prevalence of encephalitis B in Shandong Province. J Pathog Biol 2010; 4: 301-303.

Address correspondence to: Peng Cheng Shandong Institute of Parasitic Diseases Shandong Academy of Medical Sciences 11 Taibai Middle Road Jining 272033

Shandong Province

China

E-mail: cpzuye@aliyun.com

Maoqing Gong

Shandong Institute of Parasitic Diseases Shandong Academy of Medical Sciences

11 Taibai Middle Road

Jining 272033

Shandong Province

China

E-mail: gmq2005@163.com 